\section{Study of acrylamide level in food from vending machines}

\author{
Naceur Haouet, ${ }^{1}$ Simona Pistolese, ${ }^{1}$ \\ Raffaella Branciari, ${ }^{2}$ David Ranucci, ${ }^{2}$ \\ Maria Serena Altissimi ${ }^{1}$ \\ ${ }^{1}$ Institute for Experimental Veterinary \\ Medicine of Umbria and Marche, Perugia \\ (PG); ${ }^{2}$ Department of Veterinary \\ Medicine, University of Perugia, Perugia \\ (PG), Italy
}

\section{Abstract}

Acrylamide is a by-product of the Maillard reaction and is potentially carcinogenic to humans. It is found in a number of foods with higher concentrations in carbohydrate-rich foods and moderate levels of protein-rich foods such as meat, fish and seafood. Acrylamide levels in food distributed in vending machines placed in public areas of the city of Perugia were analysed by high-performance liquid chromatography. Samples included five different categories, depending on the characteristics of the products: i) potato chips; ii) salted bakery products; iii) biscuits and wafers; iv) sweet bakery products; v) sandwiches. A high variability in acrylamide level among different foods and within the same category was detected. Potato chips showed the highest amount of acrylamide $(1781 \pm 637 \mu \mathrm{g} / \mathrm{kg})$ followed by salted bakery products $(211 \pm 245$ $\mu \mathrm{g} / \mathrm{kg})$, biscuits and wafers $(184 \pm 254 \mu \mathrm{g} / \mathrm{kg})$, sweet bakery products $(100 \pm 72 \mu \mathrm{g} / \mathrm{kg})$ and sandwiches $(42 \pm 10 \mu \mathrm{g} / \mathrm{kg})$. In the potato chips and sandwiches categories, all of the samples revealed the presence of acrylamide, while different prevalence was registered in the other foods considered. The data of this study highlight the presence of acrylamide in different foods sold in vending machines and this data could be useful to understand the contribution of this type of consumption to human exposure to this compound.

\section{Introduction}

Over the last decades, the eating behavior of populations has changed substantially and an increasing dependence on foods consumed away from home has occurred (Bes-Rastrollo et al., 2010). This change has brought an increased consumption of fast food meals and snacks. The food industry responded to these new food habit issues by increasing the number of convenience foods and prepared meals available from vending machines that are widespread in various community settings such as worksites and schools (Losasso et al., 2015; Spanos and Hankey, 2010). The food choices offered in snack vending machines in Italy are mostly characterized by potatos chips and similar items, both sweet and salted bakery products, and other carbohydrate-rich foods such as cereal-based products (Losasso et al., 2015). These food matrices are considered to significantly contribute to consumer dietary exposure to acrylamide (EFSA, 2015). Acrylamide (AA) is a bifunctional monomer containing a reactive electron-deficient double bond and an amide group (Friedman, 2003) which is used as a chemical intermediate for the production of polyacrylamides and is identified as a heat-induced process contaminant of carbohydrate rich food (JEFCA, 2011; Yaylayan et al., 2003). The Maillard reaction of asparagine and reducing sugars is considered the most probable mechanism of formation (Mottram et al., 2002; Stadler et al., 2002; Zyzak et al., 2003), although contribution of lipid oxidation products in fatty rich foods is relevant (Zamora and Hidalgo, 2008). The compound was classified as probably carcinogenic to humans (Group 2A) by the International Agency for Research on Cancer (IARC, 1994), and the World Health Organization (JEFCA, 2011) considers this fact as a matter of concern to human health. The European Food Safety Authority has confirmed that the presence of acrylamide in food is a public health concern requiring continued efforts to reduce exposure to it (EFSA, 2015).

In order to regulate and control the risk associated with acrylamide intake, the European Commission established recommendations on the monitoring of acrylamide levels in foods (European Commission, 2010) and adopted indicative values to control acrylamide content in certain foodstuffs (European Commission, 2013). The aim of this study was to determine levels of acrylamide in food acquired from vending machines. These foods make a significant contribution to the food intake outside the home. The research has been intentionally limited to commercially available automatic food vending machines placed in public areas of the city of Perugia to supply useful data to estimate how the habit of consuming this food concurs with exposure to acrylamide assumption.

\section{Materials and Methods}

A total of 97 samples were analyzed for both the presence and the amount of AA (Table 1). Food samples were randomly collected from 20 vending machines in Perugia. The vending machines were located in public areas including hospitals, universities and schools.
Correspondence: Raffaella Branciari, Department of Veterinary Medicine, University of Perugia, via San Costanzo 4, 06126 Perugia (PG), Italy Tel.: +39.075.5857932 - Fax: +39.075.5857932.

E-mail: raffaella.branciari@unipg.it

Key words: Acrylamide; Fast food; Vending machines; HPLC.

Conflict of interest: the authors declare no potential conflict of interest.

Received for publication: 8 July 2016. Revision received: 23 August 2016.

Accepted for publication: 29 August 2016.

This work is licensed under a Creative Commons Attribution-NonCommercial 4.0 International License (CC BY-NC 4.0).

(C) Copyright N. Haouet et al., 2016

Licensee PAGEPress, Italy

Italian Journal of Food Safety 2016; 5:6147

doi:10.4081/ijfs.2016.6147

Samples were divided into 5 main groups depending on the different characteristics of the products: i) potato chips (crunchy thin slices or small sticks of deep-fried/baked potato usually eaten as snacks); ii) salted bakery products (crackers and similar items such as breadsticks, taralli, crisp breads and mini bagels) made with wheat flour and whole wheat flour; iii) biscuits and wafers (with and without chocolate, with and without fillings, made with wheat flour and whole wheat flour); iv) sweet bakery products (small cake or sponge cake based products with or without chocolate); and v) sandwiches (soft bread with cheese and ham).

The samples were prepared according to the method previously reported by Shi et al. (2009) with some modifications. A finely ground sample $(0.5 \mathrm{~g})$ was weighed and placed into a 50 mL centrifuge tube to which $10 \mathrm{~mL}$ of high purity de-ionized water, obtained using a MilliQ water purification system (Millipore, Bedford, MA, USA), was added. The mixture was shaken vigorously for $10 \mathrm{~min}$ using a vortex oscillator then centrifuged at $8000 \mathrm{rpm}$ for $10 \mathrm{~min}$. Five $\mathrm{mL}$ of supernatant was transferred into a $50 \mathrm{~mL}$ tube and $50 \mu \mathrm{L}$ of sodium hydroxide $0.1 \mathrm{M}$ was added. Then the $\mathrm{pH}$ of the solution was adjusted to $8 \pm 0.3$. After the addition of 2-mercaptobenzoic acid, the mixture was treated with ultrasound for $100 \mathrm{~min}$ in the dark. Then, $1 \mathrm{~mL}$ of saturated Lead (II) acetate trihydrate solution was added and centrifuged at $8000 \mathrm{rpm}$ for $10 \mathrm{~min}$. The supernatant was transferred into a $50 \mathrm{~mL}$ centrifuge tube and the $\mathrm{pH}$ was acidified until 1.5 with $\mathrm{HCl} 3 \mathrm{M}$. After centrifugation at $8000 \mathrm{rpm}$ for $10 \mathrm{~min}$, the supernatant was transferred into a $20 \mathrm{~mL}$ glass centrifuge tube and was extracted with 
ethyl acetate $(2 \times 4 \mathrm{~mL})$. The organic phase was evaporated at $70^{\circ} \mathrm{C}$ and the residue was redissolved in $250 \mu \mathrm{L}$ of methanol. The acrylamide evaluation was performed with high-performance liquid chromatography (HPLC) analysis using a Shimadzu (Kyoto, Japan) instrument model RF-20AXS consisting of a vacuum degasser, a quaternary pump, an autosampler, a thermostated column compartment, and a diode array detector (DAD). The calibration standards and sample extracts were injected via a $10 \mu \mathrm{L}$ sample loop onto a C18 RP column (250x4.6 mm, Phenomenex Inc, Torrance, CA, USA) thermostated at $25^{\circ} \mathrm{C}$. The detection wavelength was $238 \mathrm{~nm}$. A mixture of acetronitrile and acetic acid (1.0 g/L water solution) $(20: 80 \mathrm{v} / \mathrm{v})$ was used as the mobile phase. Peaks in the chromatograms were identified by comparing the retention time and UV spectrum with standard solutions of acrylamide (AA 99\% standards; SIGMA-Fluka, St. Louis, MO, USA). Acrylamide standard solution was used to construct a linear calibration curve in the range of 5 to $3000 \mu \mathrm{g} / \mathrm{L}(\mathrm{Y}=389.91 \mathrm{x}-918.19$ $\left.\mathrm{R}^{2}=0.9999\right)$. The method was in-house validated with the limit of detection being $20 \mu \mathrm{g} / \mathrm{kg}$ and the limit of quantification was $60 \mu \mathrm{g} / \mathrm{kg}$. Intermediate precision (repeatability) was $23 \%$, recovery was $96 \pm 7 \%$ and uncertainty $16 \%$. The reproducibility of the results has been demonstrated in an inter-laboratory comparison study launched by the Food Analysis Performance Assessment Scheme (FAPAS) programme (2015) with the FAPAS Proficiency Test 3057 yielding a z-score of -1.1.

\section{Results and Discussion}

The occurrences and the mean quantities of AA in the samples are reported in Figure 1 and Table 2. A high variability in acrylamide level among different foods and within the same category was detected. Potato chips showed the highest amount of AA $(1781 \pm 637 \mu \mathrm{g} / \mathrm{kg})$ followed by salted bakery products $(211 \pm 245$ $\mu \mathrm{g} / \mathrm{kg})$, biscuits and wafers $(184 \pm 254 \mu \mathrm{g} / \mathrm{kg})$, sweet bakery products $(100 \pm 72 \mu \mathrm{g} / \mathrm{kg})$ and finally sandwiches $(42 \pm 10 \mu \mathrm{g} / \mathrm{kg})$. In the potato chips and sandwiches categories, all the samples revealed the presence of acrylamide (potato sticks: $2152 \pm 353 \mu \mathrm{g} / \mathrm{kg}$; potato crisps: $965 \pm 45 \mu \mathrm{g} / \mathrm{kg}$; sandwiches: $42 \pm 10 \mu \mathrm{g} / \mathrm{kg}$ ) while in the other foods considered, different prevalences were registered. In the salted bakery products especially, AA was assessed only in taralli $(131 \pm 5 \mu \mathrm{g} / \mathrm{kg})$, mini bagels $(414 \pm 37$ $\mu \mathrm{g} / \mathrm{kg}$ ) and whole-wheat flour breadsticks $(385 \pm 287 \mu \mathrm{g} / \mathrm{kg})$.

The highest values of AA in biscuits and wafers were registered in whole-wheat flour biscuits $(726 \pm 27 \mu \mathrm{g} / \mathrm{kg})$ followed by chocolate biscuits $(319 \pm 19 \mu \mathrm{g} / \mathrm{kg})$, wheat flour biscuits
$(58 \pm 44 \mu \mathrm{g} / \mathrm{kg})$ and chocolate biscuits with filling $(47 \pm 1 \mu \mathrm{g} / \mathrm{kg})$. AA was not detected only in 9 samples, mainly wafers. In the sweet bakery products, acrylamide was detected in 6 of the 10 samples. In particular, chocolate sponge cake $(160 \pm 31 \mu \mathrm{g} / \mathrm{kg})$ and muffins $(159 \pm 12$ $\mu \mathrm{g} / \mathrm{kg}$ ) registered similar values followed by croissants $(41 \pm 47 \mu \mathrm{g} / \mathrm{kg})$. The level of acrylamide in the plum cakes was below the limit of detection.

The data of this survey highlights the presence of AA in different foods sold in vending machines. This occurrence should be strongly considered as the vending market has been progressively increasing in the last decade with over 770 million snacks sold in 2015 in Italy (Confida; www.confida.com).

Regarding the potato category, the mean value registered is higher than the indicative value of $1000 \mu \mathrm{g} / \mathrm{kg}$ for potato crisps indicated by the European Commission (2013) and that reported by other authors (Pacetti et al., 2015; Powers et al., 2013). Acrylamide level monitored in potato chips (EFSA, 2012; Powers et al., 2013) showed a significant decrease in the last few years. Nevertheless, in a small proportion of samples levels of AA exceeding 2000 $\mu \mathrm{g} / \mathrm{kg}$ were still detected (Powers et al., 2013).

Table 1. Samples tested for acrylamide presence and level.

\begin{tabular}{ll}
\hline $\begin{array}{l}\text { Food group } \\
\text { Potato chips }\end{array}$ & Type of food (number of samples) \\
\hline Salted bakery products & Potato sticks (11); potato crisps (5) \\
Biscuits and wafers & $\begin{array}{l}\text { Wheat flour breadsticks (8); whole-wheat flour breadsticks (12); } \\
\text { crackers (4); mini bagels (8); crisp bread (4); taralli (4) }\end{array}$ \\
\hline $\begin{array}{l}\text { Wheat flour biscuits (12); whole-wheat flour biscuits (4); } \\
\text { chocolate biscuits (4); chocolate biscuits with fillings (2); wafers (5) }\end{array}$ \\
\hline Sweet bakery products & $\begin{array}{l}\text { Croissant (4); plumcake (2); chocolate sponge cake (2); } \\
\text { muffin with chocolate pieces (2) }\end{array}$ \\
\hline Sandwiches & Soft bread with ham and cheese (4)
\end{tabular}

Table 2. Acrylamide level in food taken from vending machines.

\begin{tabular}{lcccccc} 
Food sample & n & Mean \pm SD & Median & Range & CI of the mean Prevalence (\%) \\
Potato chips & 16 & $1781 \pm 637$ & 1827 & $906-2655$ & 340 & 100 \\
Salted bakery products & 40 & $211 \pm 245$ & 63 & $<$ LOQ-677 & 78 & 50 \\
\hline Biscuit and wafers & 27 & $184 \pm 254$ & 77 & $<$ LOQ-755 & 100 & 67 \\
Sweet bakery products & 10 & $100 \pm 72$ & 111 & $<$ LOQ-182 & 60 & 60 \\
\hline Sandwiches & 4 & $42 \pm 10$ & 42 & $33-50$ & 15 & 100 \\
\hline
\end{tabular}

$\mathrm{SD}$, standard deviation; $\mathrm{CI}$, confidence interval; LOQ: limit of quantification. Results are expressed as a mean values $\pm \mathrm{SD}(\mu \mathrm{g} / \mathrm{kg})$.

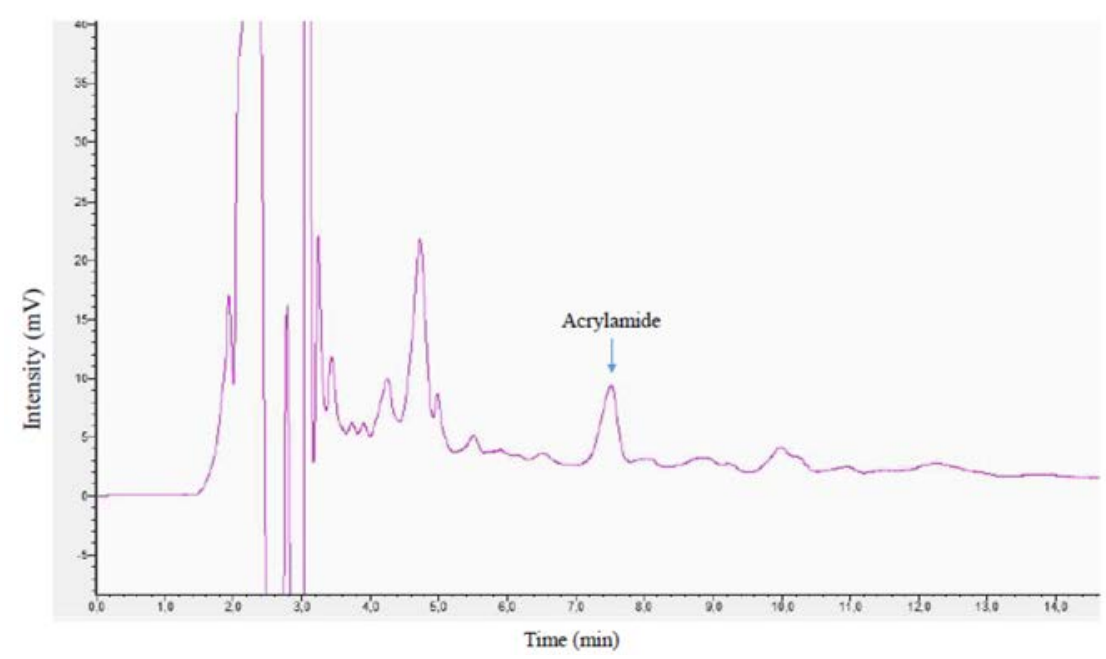

Figure 1. High-performance liquid chromatogram of acrylamide extracted from potato chips sample. Conditions: C18 RP column $(250 \times 4.6 \mathrm{~mm})$; mobile phase, acetronitrile/acetic acid

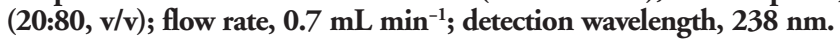


This level is comparable with that registered in potato sticks. The differences in the AA levels recorded among the same kind of potato chips could be related to differences in the content of reducing sugar and amino acids in the raw material as well as to the processing conditions. Furthermore, the importance of the processing and the structure of foods (Pacetti $e t$ $a l ., 2015)$ are highlighted by the difference recorded between sticks and crisps.

The analyses of the data derived from the other categories are not easily comparable to that referred by other authors because of the variety of ingredients used and of the different processes adopted. For example, higher levels of AA were recorded in whole-wheat flour products, both salted and sweet, than common wheat flour products and this is due to the presence of wheat-bran that is rich in asparagine (Rufian-Henares et al., 2007).

However, AA was not detected in some whole-wheat flour products samples. The level of acrylamide in analyzed crackers samples was below the LOQ but both the European Commission 2013 and other authors (Pacetti et al., 2015) indicate high level of AA in these products $(500 \mu \mathrm{g} / \mathrm{kg}$ and $758 \mu \mathrm{g} / \mathrm{kg}$ respectively). Similar findings were recorded for wafers (1440 $\mu \mathrm{g} / \mathrm{kg})$ (Pacetti et al., 2015). This wide range of variability is also reported by the EFSA (2015) for all the categories considered. Furthermore, the level of AA could be strongly influenced by the presence of both baked products and other foods combined, such as in sandwiches. The presence of the filling characterized by protein foods, that generally have low amount of AA (Swedish National Food Administration, 2002), reduced the total amount in the samples.

\section{Conclusions}

Different acrylamide levels were detected in vending snacks and the differences observed in the AA content may result from several factors. The consumption of snacks from vending services contributes to the total human exposure to this toxic compound but, to date, only few countries have set limits for its presence in foods. Therefore, monitoring the level of AA is of utmost importance for producers to raise awareness of AA reduction in food and to reduce the risk for consumers.

\section{References}

Bes-Rastrollo M, Basterra-Gortari FJ, SanchezVillegas A, Marti A, Martínez JA, MartínezGonzález MA, 2010. A prospective study of eating away-from-home meals and weight gain in a Mediterranean population: the SUN (Seguimiento Universidad de Navarra) cohort. Public Health Nutr 13:1356-63.

EFSA, 2012. Update on acrylamide levels in food from monitoring years 2007 to 2010 . EFSA J 10:2938-76.

EFSA, 2015. Scientific opinion on acrylamide in food. EFSA J 13:4104.

European Commission, 2010. Commission recommendation of 2 June 2010 on the monitoring of acrylamide levels in food. In: Official Journal, L 137, 3.6.2010.

European Commission, 2013. Commission recommendation of 8 November 2013 on investigations into the levels of acrylamide in food. In: Official Journal, L 301, 12.11.2013.

Friedman M, 2003. Chemistry, biochemistry, and safety of acrylamide. A review. J Agr Food Chem 51:4504-26.

IARC, 1994. Some industrial chemicals. IARC Publ 60:1-560.

JECFA, 2011. Evaluation of certain contaminants in food. Joint FA0/WHO Expert Committee on Food Additives, Rome, Italy.

Losasso C, Cappa V, Neuhouser ML, Giaccone V, Andrighetto I, Ricci A, 2015. Students' consumption of beverages and snacks at school and away from school: a case study in the north east of Italy. Front Nutr 2:30. Mottram DS, Wedzicha BL, Dodson AT, 2002.
Food chemistry: acrylamide is formed in the Maillard reaction. Nature 419:448-9.

Pacetti D, Gil E, Frega NG, Álvarez L, Dueñas P, Garzón A, Lucci P, 2015. Acrylamide levels in selected Colombian foods. Food Addit Contam B 8:99-105.

Powers SJ, Mottram DS, Curtis A, Halford NG, 2013. Acrylamide concentrations in potato crisps in Europe from 2002 to 2011. Food Addit Contam A 30:1493-500.

Rufian-Henares JA, Arribas-Lorenzo G, Morales FJ, 2007. Acrylamide content of selected Spanish foods: survey of biscuits and bread derivatives. Food Addit Contam 24:343-50.

Shi Z, Zhang H, Zhao X, 2009. Ultrasonicassisted precolumn derivatization-HPLC determination of acrylamide formed in Radix Asparagi during heating process. Journal Pharmaceut Biomed 49:1045-7.

Spanos D, Hankey CR, 2010. The habitual meal and snacking patterns of university students in two countries and their use of vending machines. J Hum Nutr Diet 23:102-7.

Stadler RH, Blank I, Varga N, Robert F, Hau J, Guy AP, Robert MC, Rieliker S, 2002. Acrylamide formed in the Maillard reaction. Nature 419:449.

Swedish National Food Administration, 2002. The National Food Administration, Acrylamide in heat-processed foods. Swedish National Food Administration, Uppsala, Sweden.

Yaylayan VA, Wnorowski A, Perez Locas C, 2003. Why asparagine needs carbohydrates to generate acrylamide. J Agr Food Chem 51:1753-7.

Zamora R, Hidalgo FJ, 2008. Contribution of lipid oxidation products to acrylamide formation in model systems. J Agr Food Chem 56:6075-80.

Zyzak DV, Sanders RA, Stojanovic M, Tallmadge DH, Eberhart BL, Ewald D K, Villagran MD, 2003. Acrylamide formation mechanism in heated foods. J Agr Food Chem 51:4782-7. 